\title{
CULTIVARES DE MILHO E DE GRAMÍNEAS FORRAGEIRAS SOB MONOCULTIVO E CONSORCIAÇÃO ${ }^{1}$
}

\author{
Adriano Jakelaitis ${ }^{2}$,Thales Augusto Duarte Daniel ${ }^{3}$, \\ Emerson Alexandrino ${ }^{4}$, Lindomar Pereira Simões ${ }^{5}, K_{\text {Kennedy Vidal Souza }}^{5}$, Josia Ludtke ${ }^{5}$
}

\section{ABSTRACT \\ MAIZE AND FORAGE GRASS CULTIVARS UNDER MONOCROPPING AND INTERCROPPING SYSTEMS}

The purpose of this study was to evaluate the performance of maize and forage grass (Brachiaria brizantha and Panicum maximum) cultivars under monocropping and intercropping systems. The experiment was carried out in randomized complete blocks, in a $3 \times 4+7$ factorial design, with four replications. The first factor consisted of three maize cultivars (AL Bandeirantes, an open pollination variety; AG 2040, a double cross; and Pioneer 30F87, a triple cross) and the second one included four forage cultivars (Marandu and Xaraés, from $B$. brizantha, and Tanzânia and Mombaça, from $P$. maximum). The seven additional treatments consisted of the respective tested cultivars monocroppings. Maize and forage grasses were sown simultaneously, the first in rows, spaced $1.0 \mathrm{~m}$ apart, and the second by throwing. Hybrid Pioneer 30F87 maize yields were the highest ones, for both monocropping and intercropping systems, and maize affected dry weight gain of forages, when compared to the monocropping system. For intercropping, $P$. maximum forage cultivars were the most productive ones, while, for monocropping, the Mombaça cultivar presented the highest dry matter production level.

KEY-WORDS: Zea mays; Brachiaria brizantha; Panicum maximum; agriculture and livestock integration; pasture.

\section{INTRODUÇÃO}

$\mathrm{O}$ aumento das necessidades humanas por alimentos tem intensificado a utilização de áreas para cultivos agrícolas, destinados à produção de grãos e gramíneas forrageiras, para a formação de pastos.

\section{RESUMO}

A pesquisa teve como objetivo avaliar o desempenho de cultivares de milho e de espécies forrageiras (Brachiaria brizantha e Panicum maximum), em cultivos solteiro e consorciado. O delineamento experimental foi de blocos completos casualizados, em esquema fatorial $3 \times 4+7$, com quatro repetições. $\mathrm{O}$ primeiro fator foi constituído por três cultivares de milho (variedade AL Bandeirantes, híbrido duplo AG 2040 e híbrido triplo Pioneer 30F87) e o segundo por quatro cultivares forrageiras (Marandu e Xaraés, de B. brizantha, e Tanzânia e Mombaça, de P. maximum). Os sete tratamentos adicionais corresponderam aos respectivos monocultivos das cultivares testadas. A semeadura do milho foi realizada no espaçamento de 1,0 m entre fileiras e as forrageiras foram semeadas a lanço, em semeadura simultânea ao milho. Observou-se que o híbrido Pioneer 30F87 foi o mais produtivo, tanto em consórcio quanto sob monocultivo. O milho interferiu nos ganhos de massa seca das forrageiras, quando comparadas aos cultivos solteiros. Entre as forrageiras estabelecidas sob consórcio, as cultivares de P. maximum foram as mais produtivas, enquanto a cultivar Mombaça destacou-se com a maior massa seca produzida em monocultivo.

PALAVRAS-CHAVE: Zea mays; Brachiaria brizantha; Panicum maximum; integração agricultura-pecuária; pastagem.

Na Amazônia, a substituição da floresta primária por pastagens cultivadas constitui uma das alterações ambientais mais importantes e problemáticas deste ecossistema (Dias Filho 2003). Nesta região, a vida útil das pastagens cultivadas é reduzida, devido à implantação inadequada de espécies forrageiras, à

1. Trabalho recebido em abr./2009 e aceito para publicação em jun./2010 (nº registro: PAT 5924/ DOI: 10.5216/pat.v40i4.5924).

2. Instituto Federal Goiano, Campus de Urutaí, Departamento de Desenvolvimento Educacional, Urutaí, GO, Brasil.

E-mail: adriano.jakelaitis@pq.cnpq.br.

3. Universidade Federal do Mato Grosso, Faculdade de Agronomia e Medicina Veterinária, Departamento de Agronomia,

Cuiabá, MT, Brasil. E-mail: thalesaugustoduarte@bol.com.br.

4. Universidade Federal do Tocantins, Campus de Araguaína, Departamento de Zootecnia, Araguaína, TO, Brasil.

E-mail: e_alexandrino@yahoo.com.br.

5. Universidade Federal de Rondônia, Campus Rolim de Moura, Departamento de Agronomia, Rolim de Moura, RO, Brasil. E-mails: lindomar.engenharia@hotmail.com, kennedy_svidal@hotmail.com,josialudtke_agronomia@hotmail.com. 
não fertilização dos solos e ao manejo incorreto de pastagens, que promovem a degradação do solo e a infestação por plantas daninhas (Serrão \& Homma 1991, Dias Filho 2003).

A degradação de pastagens é um processo evolutivo de perda da produtividade da forrageira, sem possibilidade de recuperação natural, o que converge para a redução do rendimento e do desempenho animal, levando, ainda, à degradação avançada dos recursos naturais e à perda de biodiversidade (Macedo 2002). Dependendo do grau e da causa desta degradação, torna-se necessário adotar diferentes estratégias de intervenção, para recuperar o potencial produtivo do pasto e desestimular a abertura de novas áreas de maior fertilidade natural de floresta (Dias Filho 2003).

A adoção de sistemas de produção diferenciados, como os cultivos consorciados e a integração agricultura-pecuária, constitui-se em importante estratégia na recuperação de pastagens degradadas, principalmente no que tange à melhoria das propriedades do solo e à diversificação da produção agropecuária (Souza Neto 1993, Cobucci 2001). Na integração agricultura-pecuária, algumas culturas, como o milho, têm sido utilizadas em consórcios, para o estabelecimento de forrageiras, com o objetivo de atenuar as despesas relativas de correção, adubação e preparo do solo, controle de plantas daninhas e renovação de pastos degradados (Souza Neto 1993, Kluthcouski et al. 2003). Por outro lado, a eficiência agronômica dos consórcios entre culturas e forrageiras depende de certas condições que são particulares a cada ambiente.

De acordo com Ferreira (2000), os sistemas consorciados podem ser aditivos ou de substituição. No sistema aditivo, ocorre a semeadura de uma das culturas, no mesmo arranjo do monocultivo, sendo a segunda cultura, simultaneamente, adicionada, aumentando-se a população de plantas na área. No consórcio de substituição, uma segunda cultura é implantada, quando a principal já foi instalada. A compatibilidade entre espécies, fertilidade do solo, ocorrência de plantas daninhas e o conhecimento de como as espécies consorciadas interagem são de grande importância para o sucesso no estabelecimento da forrageira e, também, na produção satisfatória da cultura e na relação custo-benefício, associada à renovação do pasto (Silva et al. 2004).

Em Rondônia, a pecuária é uma das atividades que mais tem se expandido e, atualmente, estima-se que cerca de 4,5 milhões de hectares da Floresta Amazônica estejam ocupados com pastagens cultivadas. Todavia, pelo menos $40 \%$ destas áreas encontram-se em diferentes graus de degradação, o que tem levado à derrubada de outras áreas de vegetação natural, para a manutenção dos rebanhos, em regime de pecuária itinerante (Costa et al. 2006). Dessa forma, um dos grandes desafios da atualidade é transformar áreas degradadas em produtivas, com potenciais econômico e ecológico sustentáveis.

Neste contexto, o objetivo desta pesquisa foi avaliar o desempenho de cultivares de milho e de espécies forrageiras (Brachiaria brizantha e Panicum maximum), sob monocultivo e consorciação, no que concerne ao rendimento destas espécies e à formação de pastagem.

\section{MATERIAL E MÉTODOS}

O experimento foi conduzido entre outubro de 2007 e julho de 2008, na Fazenda Experimental da Fundação Universidade Federal de Rondônia (Unir), em Rolim de Moura, RO (1148'13"S, 6148'12"W e $277 \mathrm{~m}$ de altitude). $\mathrm{O}$ solo da área experimental foi classificado como Latossolo Amarelo distrófico, de textura argilosa. O clima é equatorial, com variação para tropical quente e úmido, com temperaturas de $40^{\circ} \mathrm{C}$, para as máximas, e $18^{\circ} \mathrm{C}$, para as mínimas, e umidade relativa do ar de $80 \%$ a $85 \%$. A precipitação anual é elevada, com variação entre $2.000-2.500 \mathrm{~mm} /$ ano, com as estações seca e chuvosa bem definidas, sendo esta última compreendida entre os meses de outubro e abril (Rondônia 2007).

A área experimental, cultivada anteriormente com Brachiaria brizantha, foi dessecada com o herbicida sistêmico glyphosate, na dose de $1.800 \mathrm{~g} \mathrm{ha}^{-1}$, realizando-se, posteriormente, a coleta de solo, na profundidade de $20 \mathrm{~cm}$, para análise química. $\mathrm{A}$ análise deste solo apresentou $\mathrm{pH}$ em água de 5,29; 3,9 $\mathrm{cmol}_{\mathrm{c}} \mathrm{dm}^{-3} \mathrm{de} \mathrm{H}+\mathrm{Al} ; 1,1 \mathrm{cmol}_{\mathrm{c}} \mathrm{dm}^{-3} \mathrm{de} \mathrm{Ca}$; 0,4 $\mathrm{cmol}_{\mathrm{c}} \mathrm{dm}^{-\mathrm{c}}$ de $\mathrm{Mg} ; 5,6 \mathrm{cmol}_{\mathrm{c}} \mathrm{dm}^{-3}$ de CTC(T); $5,0 \mathrm{mg} \mathrm{dm}^{-3}$ de P; 0,32 $\mathrm{mmol}_{\mathrm{c}} \mathrm{dm}^{-3}$ de K; e $25 \mathrm{dag} \mathrm{kg}^{-1}$ de matéria orgânica. O preparo do solo foi realizado sob sistema convencional, por meio de subsolagem e duas gradagens, aos trinta dias após a dessecação química de B. brizantha.

Foi adotado o delineamento experimental em blocos casualizados, em esquema fatorial $3 \times 4+7$, com quatro repetições. O primeiro fator foi constituído pelas cultivares de milho: AL Bandeirantes 
(variedade de polinização aberta), AG 2040 (híbrido duplo) e Pioneer 30F87 (híbrido triplo modificado). $\mathrm{O}$ segundo fator foi representado pelas cultivares forrageiras Marandu e Xaraés, de B. brizantha, e Mombaça e Tanzânia, de P. maximum. Os sete tratamentos adicionais corresponderam aos respectivos monocultivos das cultivares testadas, tanto de milho como das forrageiras. A semeadura do milho foi manual e realizada em 01 nov. 2007. Para cada arranjo, cultivos solteiros de milho e das espécies forrageiras foram conduzidos como tratamentos adicionais.

A semeadura das cultivares de milho foi realizada no espaçamento de 1,0 $\mathrm{m}$ entre fileiras, utilizando-se sete sementes por metro, semeadas à profundidade de $5 \mathrm{~cm}$. Juntamente com as sementes, aplicou-se, no sulco de plantio, carbofuran, na dose de $525 \mathrm{~g}$ para $100 \mathrm{~kg}$ de sementes. Cada parcela foi constituída por cinco fileiras de $6,0 \mathrm{~m}$ de comprimento. A adubação de plantio do milho constou da aplicação de $450 \mathrm{~kg} \mathrm{ha}^{-1}$ da formulação 4-30-16 (N-P-K), sendo aplicados mais $100 \mathrm{~kg} \mathrm{ha}^{-1}$ de N, em cobertura, no estágio de cinco a seis folhas desenvolvidas, utilizando-se a ureia como fonte nitrogenada.

As forrageiras foram semeadas a lanço, simultaneamente ao milho, na densidade de $5 \mathrm{~kg} \mathrm{ha}^{-1}$ de sementes viáveis, com $76 \%$ de valor cultural. A adubação das forrageiras, sob monocultivo, foi feita também a lanço, por ocasião da semeadura, aplicando-se $250 \mathrm{~kg} \mathrm{ha}^{-1}$ da formulação 4-30-16. Em cobertura, foram aplicados mais $50 \mathrm{~kg} \mathrm{ha}^{-1} \mathrm{de} \mathrm{N}$, aos quarenta dias após a emergência (DAE), tendo a ureia, também, como fonte nitrogenada.

Como tratamento fitossanitário, utilizou-se, aos 25 DAE do milho, o inseticida chlorpiriphos, na dose de $450 \mathrm{~g} \mathrm{ha}^{-1}$, visando ao controle de Spodoptera frugiperda e das cigarrinhas Deois spp. e Mahanarva fimbriolata. Aos 20 DAE, foi utilizado o herbicida atrazine $\left(1000 \mathrm{~g} \mathrm{ha}^{-1}\right)$, em decorrência da infestação de plantas daninhas, principalmente Ipomoea spp. e Acanthospermum hispidum.

O milho foi colhido manualmente, em 10 mar. 2008, e, em pré-colheita, foram determinadas as seguintes variáveis: altura de plantas (distância média da superfície do solo até a inserção da folha-bandeira, em dez plantas ao acaso, de cada parcela); altura de espigas (distância média da superfície do solo até a inserção da espiga); diâmetro de colmo (medição direta na base da planta, com uso de paquímetro); estande (número de plantas na área útil da parcela, no momento da colheita); massa seca da parte aérea (amostragem, corte e pesagem da parte aérea de seis plantas tomadas ao acaso, na área útil da parcela, seguidas de subamostragem de material levado à estufa, a $65^{\circ} \mathrm{C}$, até peso constante, convertendo-se a massa seca obtida em $\mathrm{kg} \mathrm{ha}^{-1}$ ); prolificidade (número de espigas por planta); rendimento de grãos na área útil, corrigida para $13 \%$ de umidade; massa de cem grãos, corrigida para 13\% de umidade; e índice de colheita (relação entre o rendimento de grãos e a massa seca total da planta).

Para a forrageira $B$. brizantha, foram avaliadas a massa seca total da parte aérea e a relação folha:colmo. As avaliações de massa seca foram realizadas por meio de amostragem, em área de 1,0 $\mathrm{m}^{2}$ na parcela, onde as plantas coletadas foram separadas em folhas, colmo e material morto, e, em seguida, secas em estufa de ventilação forçada, a $65^{\circ} \mathrm{C}$, até atingir massa constante, sendo, posteriormente, pesadas. Estas avaliações foram realizadas em 05 fev., 05 abr. e 15 jul. 2008, nas parcelas em monocultivo (tratamentos testemunhas), e apenas nas duas últimas datas, para os demais tratamentos. Após cada avaliação, foram realizados cortes, a $20 \mathrm{~cm}$ do solo, para uniformização da altura das plantas forrageiras.

Os dados obtidos foram submetidos a análise de variância e, quando os efeitos de tratamentos foram significativos $(\mathrm{p}<0,05)$, realizou-se a comparação de suas médias pelo teste Tukey, a 5\% de probabilidade. Utilizou-se, também, o teste de Dunnet, para comparações entre médias de tratamentos com a respectiva testemunha (para o milho adotou-se, como testemunha, a variedade AL Bandeirantes e, para as forrageiras, B. brizantha $\mathrm{cv}$. Marandu).

\section{RESULTADOS E DISCUSSÃO}

Os resultados das variáveis agronômicas avaliadas nas cultivares de milho, sob monocultivo ou em consorciação, referentes às alturas de plantas e de espigas, ao diâmetro do colmo e à população de plantas, estão apresentados na Tabela 1. Não foram observados efeitos significativos para a interação das cultivares de milho com as cultivares forrageiras. No entanto, em consórcio, verificou-se efeito significativo entre as cultivares de milho, tendo a cultivar $\mathrm{AL}$ Bandeirantes se destacado com plantas mais altas, em relação às demais, enquanto Pioneer 30F87 apresentou plantas mais baixas (Tabela 1).

Comparando-se as alturas das plantas de milho, nos sistemas consorciado e solteiro, com a teste- 
Tabela 1. Alturas de plantas (AP) e de espigas (AE), diâmetro de colmo (DC) e estande em cultivares de milho sob consórcio com forrageiras ou em monocultivo (Rolim de Moura, RO, safra 2007/2008).

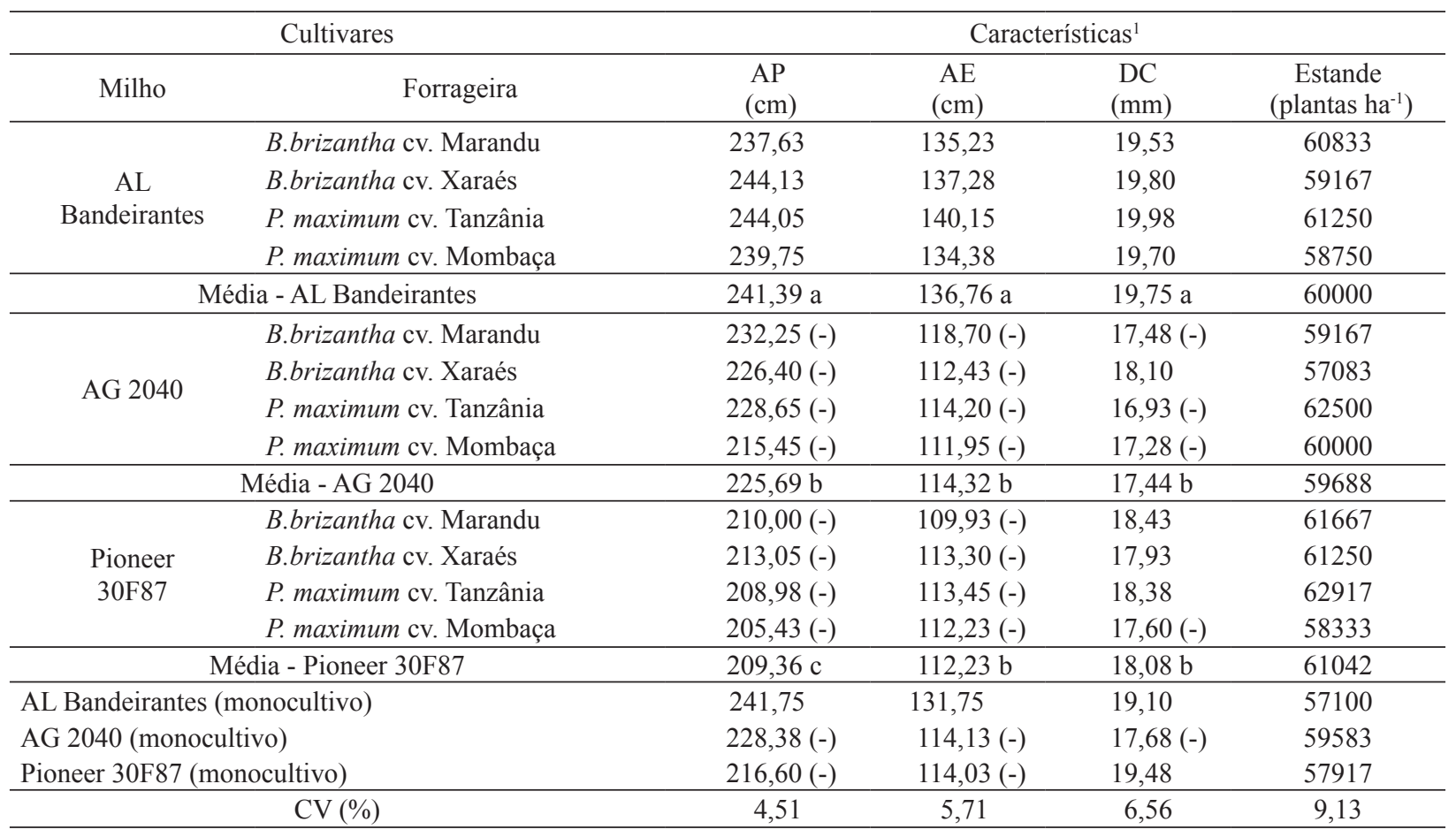

${ }^{1}$ Letras minúsculas, nas colunas, comparam as médias pelo teste Tukey, a 5\% de probabilidade. As médias seguidas de (-) foram inferiores à testemunha (AL Bandeirantes, em monocultivo), pelo teste de Dunnet, a $5 \%$ de probabilidade.

munha (AL Bandeirantes solteira), observou-se que a presença das forrageiras estabelecidas em consórcio não comprometeu o desempenho desta variável. Além disso, as cultivares AG 2040 e Pioneer 30F87, independentemente de serem cultivadas em monocultivo ou consórcio, apresentaram alturas inferiores à testemunha (Tabela 1$)$.

Jakelaitis et al. (2006), avaliando os efeitos de densidade e época de emergência de $B$. brizantha, em competição com plantas de milho, verificaram que, à medida em que a forrageira se antecipa ao estabelecimento do milho, maior é o grau de interferência da forrageira sobre a altura das plantas, diâmetro do colmo, massa seca da parte aérea e rendimento de grãos de milho, e esta interferência é intensificada pelo aumento da densidade de B. brizantha. Porém, Cobucci (2001) comenta que a ausência de diferença estatística para estas variáveis, em consórcios de milho com Brachiaria spp., em semeadura simultânea, pode ser explicada pelo fato de as braquiárias apresentarem crescimento inicial lento, não interferindo, desta forma, sobre o desenvolvimento do milho.

Por outro lado, a altura de espigas foi superior na variedade AL Bandeirantes, em relação aos híbri- dos AG 2040 e Pioneer 30F87, tanto nos sistemas consorciados quanto em monocultivo (Tabela 1). Esta característica é importante, neste sistema de consórcio, pois pode influenciar, diretamente, na colheita, haja vista que plantas com reduzida altura de espiga podem comprometer a operação de colheita, principalmente se esta for mecanizada (obstrução da plataforma de corte pela forragem). No caso das cultivares avaliadas nesta pesquisa, todas resultaram em alturas de espiga desejáveis, não havendo, portanto, razão para se preocupar com este tipo de interferência, em decorrência do sistema de cultivo.

Para o diâmetro do colmo, no milho, não houve interação significativa das suas cultivares com as forrageiras consorciadas. Foi observada diferença significativa somente entre a cultivar AL Bandeirantes, com colmos mais grossos, e os híbridos (Tabela 1), independentemente de o sistema ser em monocultivo ou consorciado. Comparativamente à testemunha, apenas a cultivar AG 2040, sob monocultivo, apresentou colmos mais finos. Já no que se refere à população de plantas (estande), não se observou interferência dos tratamentos, ficando esta população entre 57.000 e 63.000 indivíduos por hectare (Tabela 1). 
Na Tabela 2, são apresentados os resultados de massa seca da parte aérea, prolificidade, índice de colheita e massa de cem grãos, para as cultivares de milho, nos sistemas de cultivo solteiro e consorciado. Como observado anteriormente, para estas variáveis, não foram verificadas interações significativas das cultivares de milho com as forrageiras sob consorciação. No entanto, observaram-se efeitos significativos entre as cultivares de milho, para o índice de colheita, o que deve ter decorrido da diferença significativa entre tratamentos encontrada para o rendimento de grãos (Tabela 3). Os baixos valores observados para índice de colheita justificam-se pelo, também, reduzido rendimento de grãos, próprio de cultivos de milho na região Amazônica, haja vista as temperaturas elevadas e as baixas altitudes (Durães et al. 2002, Fidelis et al. 2009). Para prolificidade, massa seca da parte aérea e massa de cem grãos, a análise dos resultados não evidenciou diferenciação significativa entre os tratamentos, seja em consórcio ou monocultivo, indicando que a consorciação não exerceu efeito sobre estas variáveis.

Tabela 2. Massa seca da parte aérea (MSPA), prolificidade (PF), índice de colheita (IC) e massa de cem grãos (MCG), em cultivares de milho sob consórcio com forrageiras e em monocultivo (Rolim de Moura, RO, safra 2007/2008).

\begin{tabular}{|c|c|c|c|c|c|}
\hline \multicolumn{2}{|r|}{ Cultivares } & \multicolumn{4}{|c|}{ Características $^{1}$} \\
\hline Milho & Forrageira & $\begin{array}{c}\mathrm{MS} \\
\left(\mathrm{kg} \mathrm{ha}^{-1}\right)\end{array}$ & $\begin{array}{c}\text { PF } \\
\left(\text { espiga pl }^{-1}\right)\end{array}$ & IC & $\begin{array}{c}\mathrm{MCG} \\
(\mathrm{g})\end{array}$ \\
\hline \multirow{4}{*}{$\begin{array}{c}\text { AL } \\
\text { Bandeirantes }\end{array}$} & B.brizantha $\mathrm{cv}$. Marandu & 16306 & 0,98 & 0,27 & 28,97 \\
\hline & B.brizantha cv. Xaraés & 17957 & 0,96 & 0,25 & 27,21 \\
\hline & P. maximum cv. Tanzânia & 17313 & 0,91 & 0,24 & 27,73 \\
\hline & P. maximum cv. Mombaça & 17525 & 0,91 & 0,26 & 28,16 \\
\hline \multicolumn{2}{|c|}{ Média - AL Bandeirantes } & 17275 & 0,94 & $0,25 \mathrm{~b}$ & 28,02 \\
\hline \multirow{4}{*}{ AG 2040} & B.brizantha $\mathrm{cv}$. Marandu & 18085 & 0,98 & $0,31(+)$ & 29,66 \\
\hline & B.brizantha cv. Xaraés & 17771 & 0,99 & $0,32(+)$ & 28,28 \\
\hline & P. maximum cv. Tanzânia & 17806 & 0,95 & 0,27 & 27,01 \\
\hline & P. maximum cv. Mombaça & 17911 & 1,01 & 0,26 & 26,78 \\
\hline & edia - AG 2040 & 17893 & 0,98 & $0,29 \mathrm{a}$ & 27,93 \\
\hline \multirow{4}{*}{$\begin{array}{c}\text { Pioneer } \\
30 \mathrm{~F} 87\end{array}$} & B.brizantha cv. Marandu & 17333 & 0,99 & $0,36(+)$ & 28,43 \\
\hline & B.brizantha cv. Xaraés & 18514 & 0,98 & $0,33(+)$ & 28,29 \\
\hline & P. maximum cv. Tanzânia & 18419 & 0,96 & 0,29 & 27,69 \\
\hline & P. maximum cv. Mombaça & 17052 & 0,94 & 0,30 & 26,53 \\
\hline \multicolumn{2}{|c|}{ Média - Pioneer 30F87 } & 17830 & 0,97 & $0,32 \mathrm{a}$ & 27,73 \\
\hline \multicolumn{2}{|c|}{ AL Bandeirantes (monocultivo) } & 18312 & 0,94 & 0,26 & 28,44 \\
\hline \multicolumn{2}{|c|}{ AG 2040 (monocultivo) } & 17142 & 0,94 & $0,33(+)$ & 28,02 \\
\hline \multicolumn{2}{|c|}{ Pioneer 30F87 (monocultivo) } & 18447 & 0,97 & $0,34(+)$ & 28,25 \\
\hline & CV $(\%)$ & 17,41 & 6,21 & 12,96 & 5,64 \\
\hline
\end{tabular}

${ }^{1}$ Letras minúsculas, nas colunas, comparam as médias pelo teste Tukey, a $5 \%$ de probabilidade. As médias seguidas de $(+)$ foram superiores à testemunha (AL Bandeirantes, em monocultivo), pelo teste de Dunnet, a $5 \%$ de probabilidade.

Tabela 3. Rendimento de grãos em cultivares de milho sob monocultivo e em consorciação com forrageiras (Rolim de Moura, RO, safra 2007/2008).

\begin{tabular}{|c|c|c|c|c|c|c|}
\hline \multirow{3}{*}{ Cultivares de milho } & \multicolumn{6}{|c|}{ Rendimento de grãos ${ }^{1}\left(\mathrm{~kg} \mathrm{ha}^{-1}\right)$} \\
\hline & \multicolumn{2}{|c|}{ Brachiaria brizantha } & \multicolumn{2}{|c|}{ Panicum maximum } & \multirow{2}{*}{$\begin{array}{c}\text { Média } \\
\text { (consorciado) }\end{array}$} & \multirow{2}{*}{$\begin{array}{c}\text { Média } \\
\text { (monocultivo) }\end{array}$} \\
\hline & cv. Marandu & cv. Xaraés & cv. Mombaça & cv. Tanzânia & & \\
\hline AL Bandeirantes & 4448,36 & 4399,67 & 4136,98 & 4489,98 & $4368,72 \mathrm{c}$ & 4686,42 \\
\hline AG 2040 & $5521,02(+)$ & $5616,03(+)$ & 4883,76 & 4675,00 & $5173,95 \mathrm{~b}$ & $5673,73(+)$ \\
\hline Pioneer 30F87 & $6121,28(+)$ & $6205,62(+)$ & 5341,40 & 5083,71 & $5688,00 \mathrm{a}(+)$ & $6183,67(+)$ \\
\hline Média (consorciado) & $5363,55 \mathrm{~A}$ & $5407,10 \mathrm{~A}$ & $4787,38 \mathrm{~B}$ & $4749,53 \mathrm{~B}$ & - & - \\
\hline
\end{tabular}


Quanto ao rendimento de grãos, não foi observada interação significativa dos fatores testados, mas apenas efeitos principais destes fatores. Assim, entre as cultivares de milho, no sistema consorciado, a mais produtiva foi o híbrido Pioneer 30F87 e a menos produtiva a variedade AL Bandeirantes (Tabela 3). Comparadas à testemunha (solteira), as cultivares AG 2040 e Pioneer 30F87, também em monocultivo, apresentaram os maiores rendimentos. Por outro lado, analisando-se a convivência da forrageira com as cultivares de milho, observou-se que somente $P$. maximum interferiu no rendimento de grãos do milho, enquanto a convivência de $B$. brizantha não comprometeu a produtividade destas cultivares (Tabela 3).

No caso de B. brizantha, os resultados encontrados discordam de Macedo \& Zimmer (1990), Pantano (2003) e Jakelaitis et al. (2005), que detectaram redução significativa no rendimento de grãos de milho, quando esta cultura foi consorciada com a referida forrageira. Todavia, concordam com os resultados apresentados por Alvim et al. (1989), Cobucci (2001) e Jakelaitis et al. (2004), que sustentam a viabilidade agronômica do consórcio entre milho e forrageiras.

A interferência das forrageiras no estado nutricional da cultura, bem como no seu rendimento de grãos, depende das condições do solo, clima, cultivares utilizadas e do manejo empregado (Silva et al. 2004). Pantano (2003) obteve maior produtividade de milho em cultivo solteiro, comparativamente às modalidades de consorciação com forrageiras, em semeadura simultânea ou em cobertura. Segundo o autor, a competição exercida por $B$. brizantha, em consórcio estabelecido na linha de semeadura do milho, afeta o desenvolvimento da cultura, em virtude do período crítico de prevenção à interferência, que vai dos 15 aos 45 dias após a emergência, no milho.

Com relação às variáveis avaliadas nas forrageiras, os resultados da produção de massa seca e da relação folha:colmo são apresentados na Tabela 4. Observou-se que não houve interação significativa entre os fatores testados, havendo significância somente para os efeitos principais (cultivares de milho e cultivares forrageiras), na avaliação realizada após a colheita do milho (05 abr. 2008). Isto refletiu, também, em efeitos significativos sobre a massa seca acumulada pela forrageira.

Quanto às forrageiras estabelecidas sob consórcio, na primeira avaliação realizada após a colheita do milho, observou-se que as cultivares de P. maximum apresentaram maior incremento de massa seca que as cultivares de $B$. brizantha e que o híbrido de milho AG 2040 mostrou-se mais competitivo com as forra-

Tabela 4. Massa seca da parte aérea (MS) e relação folha:colmo (FC) de cultivares de espécies forrageiras, em cada período de avaliação, e rendimento forrageiro acumulado (MSAc), sob monocultivo ou consorciação com milho (Rolim de Moura, RO, safra 2007/2008).

\begin{tabular}{|c|c|c|c|c|c|c|c|}
\hline Cultivares & & & & Caracterís & $\operatorname{cas}^{1}$ & & \\
\hline Milho consorciado & $\begin{array}{c}\mathrm{MS}^{2} \\
\left(\mathrm{~kg} \mathrm{ha}^{-1}\right)\end{array}$ & $\mathrm{FC}^{2}$ & $\begin{array}{c}\mathrm{MS}^{3} \\
\left(\mathrm{~kg} \mathrm{ha}^{-1}\right)\end{array}$ & $\mathrm{FC}^{3}$ & $\begin{array}{c}\mathrm{MS}^{4} \\
\left(\mathrm{~kg} \mathrm{ha}^{-1}\right)\end{array}$ & $\mathrm{FC}^{4}$ & $\begin{array}{c}\text { MSAc } \\
\left(\mathrm{kg} \mathrm{ha}^{-1}\right)\end{array}$ \\
\hline AL Bandeirantes & - & - & 6859,75 a (-) & $1,70 \mathrm{~b}(+)$ & 10104,24 & 1,53 & 16963,99 a (-) \\
\hline AG 2040 & - & - & 4877,83 c (-) & $2,03 \mathrm{a}(+)$ & 11995,91 & 1,57 & 16873,74 a (-) \\
\hline Pioneer 30F87 & - & - & $5776,60 \mathrm{~b}(-)$ & $1,83 \mathrm{ab}(+)$ & 11630,20 & 1,54 & 17406,80 a (-) \\
\hline Forrageira consorciada & - & - & - & - & - & - & - \\
\hline B. brizantha $\mathrm{cv}$. Marandu & - & - & 3511,49 b (-) & $2,06 \mathrm{a}(+)$ & 10238,97 & 1,67 & 13750,46 b (-) \\
\hline B. brizantha cv. Xaraés & - & - & 5043,57 b (-) & $1,98 \mathrm{ab}(+)$ & 11756,77 & 1,48 & $16800,34 \mathrm{ab}(-)$ \\
\hline P. maximum cv. Mombaça & - & - & 7505,51 a (-) & $1,69 \mathrm{ab}(+)$ & 11489,07 & 1,54 & 18994,58 a (-) \\
\hline P. manicum cv. Tanzânia & - & - & 7366,56 a (-) & $1,65 \mathrm{~b}(+)$ & 11458,52 & 1,50 & 18825,08 a (-) \\
\hline Forrageira em monocultivo & - & - & - & - & - & - & - \\
\hline B. brizantha $\mathrm{cv}$. Marandu & 7498,47 & 1,01 & 9432,16 & 1,08 & 12687,76 & 1,44 & 29618,38 \\
\hline B. brizantha cv. Xaraés & 9229,19 & 1,03 & 10654,37 & 1,18 & 13354,34 & 1,37 & $33237,90(+)$ \\
\hline P. maximum cv. Mombaça & 13843,59 & 1,53 & $12179,08(+)$ & 1,20 & 14621,47 & 1,52 & $40644,15(+)$ \\
\hline P. manicum cv. Tanzânia & 10501,36 & 1,54 & $11343,38(+)$ & 1,09 & 12854,87 & 1,75 & $34699,61(+)$ \\
\hline CV $(\%)$ & - & - & 18,01 & 14,88 & 15,41 & 16,32 & 11,67 \\
\hline
\end{tabular}


geiras (Tabela 4). Observa-se, ainda, que a presença do milho suprimiu o desenvolvimento das forrageiras, independentemente das cultivares testadas. Estes resultados concordam com Portes et al. (2000), que avaliaram o crescimento de uma cultivar de braquiária em consórcio com milho, sorgo, milheto e arroz, bem como a sua rebrota, após a colheita dos cereais. Observaram, ainda, que a presença destes cereais reduziu o número de perfilhos da forrageira, seu índice de área foliar e a massa seca total da parte aérea. De acordo com Alvarenga et al. (2006), por ser uma planta muito competitiva, o milho afeta, negativamente, a forrageira, principalmente quando a implantação desta ocorre em pós-emergência ao milho.

Ressalta-se que, no intervalo compreendido entre a semeadura e a avaliação das forrageiras estabelecidas sob consórcio, as testemunhas (solteiras) foram colhidas e as cultivares de P. maximum tiveram maior ganho de massa seca, em relação à testemunha (B. brizantha cultivar Marandu) (Tabela 4). Por outro lado, observa-se que, a partir da última avaliação, o rendimento forrageiro de todas as cultivares, independentemente da forma de estabelecimento, manteve-se uniforme. Avaliando-se a massa seca acumulada, verifica-se que as testemunhas foram mais produtivas do que os cultivos consorciados, principalmente em P. maximum. De acordo com Jakelaitis et al. (2005), no consórcio, o vigor das plântulas de milho é maior, em relação às plântulas de $B$. brizantha, e, por esta razão, o crescimento inicial do milho é mais rápido, gerando competição desfavorável à forrageira e proporcionando acúmulo de massa seca à $B$. brizantha, em monocultivo, superior à produção do sistema de consórcio com o milho. Como planta dominante neste consórcio, o desenvolvimento vegetativo das forrageiras, na presente pesquisa, foi retardado, devido ao sombreamento e à competição exercida pelo milho.

Quanto à relação folha:colmo, observou-se, na avaliação realizada após a colheita das cultivares de milho (05 abr. 2008), que esta variável apresentou uma relação inversamente proporcional à massa seca produzida. Assim, manifestou maiores valores nas cultivares forrageiras estabelecidas sob consórcio, as quais foram superiores à testemunha, principalmente para as cultivares de braquiária (Tabela 4).

Segundo Cândido et al. (2005), a relação folha:colmo é uma característica que pode expressar a qualidade da forragem, sendo que uma maior participação do componente "folha" é desejável, pois esta é a porção da planta usualmente mais nutritiva e, preferencialmente, selecionada pelos animais em pastejo. Após a colheita do milho, observaram-se valores elevados desta relação nas forrageiras (entre 1,65 e 2,06), indicando que houve maior alocação de fotoassimilados e seus derivados, para a produção de folhas, em detrimento da produção de colmos. Em condições de competição por luz, segundo Kephart et al. (1992), geralmente as plantas forrageiras destinam maior quantidade de carboidratos para manter ou aumentar a área foliar e o comprimento dos colmos, em resposta ao sombreamento, ao passo que diminuem a alocação destes fotoassimilados para a produção de raízes.

Segundo Leonel et al. (2009), neste tipo de consórcio, a relação folha:colmo, em capim braquiária, decresce, quando o sombreamento proporcionado pelo dossel do milho sobre o do capim é mais intenso, em comparação ao monocultivo. Desta forma, como a avaliação de 05 abr. 2008 ocorreu 25 dias após a colheita do milho, houve incremento da área foliar das forrageiras, em detrimento do alongamento de colmos, em relação aos respectivos monocultivos (Tabela 4). Contrariamente, nas demais avaliações, não foram observados efeitos dos tratamentos sobre a relação folha:colmo. Provavelmente, após os cortes de uniformização e a colheita do milho, o crescimento da forrageira tenha sido reassumido, quando as folhas mais novas passaram a suprir as necessidades da planta.

\section{CONCLUSÕES}

1. Em relação ao rendimento de grãos das cultivares de milho, o híbrido Pioneer 30F87 mostra-se mais produtivo, independentemente da consorciação com as espécies forrageiras.

2. Em consórcio, a presença de P. maximum afeta, negativamente, o rendimento de grãos das cultivares de milho avaliadas.

3. A presença do milho afeta, negativamente, a produção de massa seca das forrageiras avaliadas, sendo esta interferência mais significativa em B. brizantha cv. Marandu.

4. Entre as forrageiras, a cultivar Mombaça, de P. maximum, mostra-se mais produtiva, independentemente da consorciação com milho.

5. Comparativamente ao sistema solteiro de cultivo, a relação folha:colmo das forrageiras estabelecidas sob consorciação é superior, após a colheita do milho. 


\section{AGRADECIMENTOS}

Ao Conselho Nacional de Desenvolvimento Científico e Tecnológico (CNPq), pelo auxílio financeiro.

\section{REFERÊNCIAS}

ALVARENGA, R. C. et al. A cultura do milho na integração lavoura-pecuária. Informe Agropecuário, Belo Horizonte, v. 27 , n. 233 , p. 106-126, 2006.

ALVIM, M. J.; BOTREL, M. A. S.; SALVATI, J. A. Métodos de estabelecimento de Brachiaria decumbens em associação com a cultura do milho. Revista Brasileira de Zootecnia, Viçosa, v. 18, n. 5, p. 417-425, 1989.

CÂNDIDO, M. J. D. et al. Morfofisiologia do dossel de Panicum maximum cv. Mombaça sob lotação intermitente. Revista Brasileira de Zootecnia, Viçosa, v. 34, n. 2, p. 406415, 2005.

COBUCCI, T. Manejo integrado de plantas daninhas em sistema de plantio direto. In: ZAMBOLIM, L. Manejo integrado fitossanidade: cultivo protegido, pivô central e plantio direto. Viçosa: UFV, 2001. p. 583-624.

COSTA, N. L. et al. Recuperação e renovação de pastagens degradadas. Revista Eletrônica de Veterinária, Málaga, v. 7, n. 1, p. 9-49, 2006.

DIAS FILHO, M. B. Degradação de pastagens: processos, causas e estratégias de recuperação. Belém: Embrapa Amazônia Oriental, 2003.

DURÃES, F. O. M.; MAGALHÃES, P. C.; OLIVEIRA, A. C. Índice de colheita genético e as possibilidades da genética fisiológica para melhoramento do rendimento de milho. Revista Brasileira de Milho e Sorgo, Sete Lagoas, v. 1, n. 1, p. 33-40, 2002.

FERREIRA, P. V. Experimentos com consorciação de culturas. In: FERREIRA, P. V. Estatística experimental aplicada à agronomia. Alagoas: UFAL, 2000. p. 361386.

FIDELES, R. R.; MIRANDA, G. V.; ERASMO, E. A. E. Seleção de populações base de milho sob alta e baixa dose de fósforo em solo de Cerrado. Pesquisa Agropecuária Tropical, Goiânia, v. 39, n. 4, p. 285-293, 2009.

JAKELAITIS, A. et al. Efeitos de densidade e época de emergência de Brachiaria brizantha em competição com plantas de milho. Acta Scientiarum, Maringá, v. 28, n. 3, p. 375-380, 2006.

JAKELAITIS, A. et al. Influência de herbicidas e de sistemas de semeadura de Brachiaria brizantha consorciada com milho. Planta Daninha, Viçosa, v. 23, n. 1, p. 59-67, mar. 2005.
JAKELAITIS, A. et al. Manejo de plantas daninhas no consórcio de milho com capim-braquiária (Brachiaria decumbens). Planta Daninha, Viçosa, v. 22, n. 4, p. 553560, 2004.

KEPHART, K. D.; BUXTON, D. R.; TAYLOR, S. E. Growth of $\mathrm{C} 3$ and $\mathrm{C} 4$ perennial grasses in reduced irradiance. Crop Science, Madison, v. 32, n. 4, p. 10331038, 1992.

KLUTHCOUSKI, J.; STONE, L. F.; AIDAR, H. Integração lavoura-pecuária. Santo Antônio de Goiás: Embrapa Arroz e Feijão, 2003.

LEONEL, F. P. et al. Comportamento produtivo e características nutricionais do capim-braquiária cultivado em consórcio com milho. Revista Brasileira de Zootecnia, Viçosa, v. 38, n. 1, p. 177-189, 2009.

MACEDO, M. C. M. Degradação, renovação e recuperação de pastagens cultivadas: ênfase sobre a região dos Cerrados. In: SIMPÓSIO SOBRE MANEJO ESTRATÉGICO DA PASTAGEM, 1., 2002, Viçosa. Anais... Viçosa: UFV, 2002. p. 85-108.

MACEDO, M. C. M.; ZIMMER, A. H. Implantação de pastagens de Brachiaria brizantha $\mathrm{cv}$. Marandu em plantio simultâneo com milho em sucessão à soja em Mato Grosso do Sul. In: REUNIÃO ANUAL DA SBZ, 27., 1990, Campinas. Anais... Campinas: SBZ, 1990. p. 290.

PANTANO, A. C. Semeadura de braquiária em consorciação com milho em diferentes espaçamentos na integração agricultura-pecuária em plantio direto. 2003. 60 f. Dissertação (Mestrado em Produção Vegetal)Faculdade de Engenharia de Ilha Solteira, Universidade Estadual Paulista, Ilha Solteira, 2003.

PORTES, T. A. et al. Análise do crescimento de uma cultivar de braquiária em cultivo solteiro e consorciado com cereais. Pesquisa Agropecuária Brasileira, Brasília, DF, v. 35, n. 7, p. 1349-1358, 2000.

RONDÔNIA. Secretaria do Estado de Desenvolvimento Ambiental (Sedam). Boletins climatológicos. 2007. Disponível em: <http://www.sedam.ro.gov.br>. Acesso em: 29 mar. 2009.

SERRÃO, E. A. S.; HOMMA, A. K. O. Agriculture in the Amazon: the question of sustainability. Washington: Committee for Agriculture and Environment in the Humid Tropics, 1991.

SILVA, A. A.; JAKELAITIS, A.; FERREIRA, L. R. Manejo de plantas daninhas no sistema integrado agricultura-pecuária. In: ZAMBOLIM, L.; SILVA, A. A.; AGNES, E. L. Manejo integrado lavoura-pecuária. Viçosa: UFV, 2004. p. 117-170.

SOUZA NETO, J. M. Formação de pastagens de Brachiaria brizantha cv. Marandu com o milho como cultura acompanhante. 1993. 58 f. Dissertação (Mestrado em Agronomia)-Escola Superior de Agricultura Luiz de Queiroz, Universidade de São Paulo, Piracicaba, 1993. 